

Life Sciences Contribution 72 Royal Ontario Museum

LIBRARY

YAL ONTARIO MUSEUM
Contributions to the Systematics of the Caddisfly Family Molannidae in Asia (Trichoptera)

Glenn B. Wiggins

ROYAL ONTARIO MUSEUM LIBRARIES

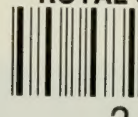

З 1761050138031

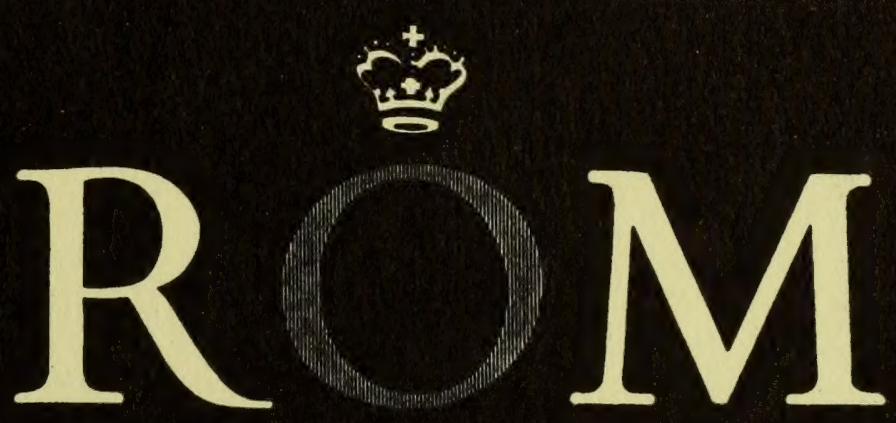


Digitized by the Internet Archive in 2011 with funding from University of Toronto 
Contribution No. 72

LIFE SCIENCES

ROYAL ONTARIO MUSEUM

glenn b. wiggins Contributions to the Systematics

of the Caddisfly Family Molannidae in Asia (Trichoptera)

Publication date: 11 July, 1968

Suggested citation: Life Sci. Contr., R. Ont. Mus.

PRICE： \$1.00 


\section{ROYAL ONTARIO MUSEUM \\ PUBLICATIONS IN LIFE SCIENCES}

The Royal Ontario Museum publishes three series in the Life Sciences:

LIFE SCIENCES CONTRIBUTIONS, a numbered series of original scientific publications, including monographic works.

LIFE SCIENCES OCCASIONAL PAPERS, a numbered series of original scientific publications, primarily short and usually of taxonomic significance.

LIFE SCIENCES MISCELLANEOUS PUBLICATIONS, an unnumbered series of publications of varied subject matter and format.

All manuscripts considered for publication are subject to the scrutiny and editorial policies of the Life Sciences Editorial Board, and to review by persons outside the Museum staff who are authorities in the particular field involved.

LIFE SCIENCES EDITORIAL BOARD, 1968

Chairman: P. C. SWANN

Director, Royal Ontario Museum

Editors: W. B. scotT

Curator, Department of Ichthyology and Herpetology

G. B. WIGGINS

Curator, Department of Entomology and Invertebrate Zoology

GLENN B. WIGGINS is Curator of the Department of Entomology and Invertebrate Zoology, Royal Ontario Museum, and Professor in the Department of Zoology, University of Toronto.

(C) The Royal Ontario Museum, 1968

PRINTED AT THE UNIVERSITY OF TORONTO PRESS 


\title{
Contributions to the Systematics of the Caddisfly Family Molannidae in Asia (Trichoptera)
}

\begin{abstract}
Study of a collection of several hundred adult caddisflies of the family Molannidae from India has yielded three new species of Molanna and five new species representing a new genus, Indomolannodes. For the new genus Indomolannodes, which is closest to Molannodes, a key to males and females of the five new species is presented. The genitalia of the male holotype of Molanna moesta Banks from Japan are illustrated and this name shown to be the senior synonym of the widespread Asian species known hitherto as $M$. falcata Ulmer. Molanna coreana Tsuda is designated a junior synonym of $M$. submarginalis McL. In the genus Molannodes variation within Eurasian material of $M$. tinctus Zett. is found to include the form described as M. bergi Ross from Alaska, and this latter name is designated a junior synonym. A key to the three Holarctic genera of the Molannidae is given.
\end{abstract}

\section{Introduction}

Between the years 1959 and 1962 Dr. Fernand Schmid, now of the Entomology Research Institute, Ottawa, collected Trichoptera in India. Included among these exceedingly rich research materials are several hundred specimens of the family Molannidae. Dr. Schmid has made the molannid material available to me and this paper presents the results of my study of it. A few specimens from other sources have been added. Dr. Schmid's specimens are divided between his own collection, where all of the holotypes are deposited, and that of the Royal Ontario Museum.

This molannid material comprises only adult specimens, with no immature stages represented. Specimens were collected by net during the day, or by attracting them to a light at night. Those taken by the latter method are so identified by the words at light. The collection is of considerable interest because of the relatively large number of new species it adds to this small family. There are three new species in the genus Molanna, and five in a genus previously unknown. During the course of the study it has become evident that several existing names are actually synonyms for other Asian species, and the appropriate changes are here proposed. 


\section{Genus Molanna Curtis}

\section{Molanna moesta Banks}

Molanna moesta Banks 1906, p. 110, pl. III, figs. 5, 6.

Molanna falcata Ulmer 1908, p. 347, figs. 8-12. NEW SYNONYMY.

Molanna falcata Martynov 1910, p. 367, figs. 15-18.

This species was originally based on a single male specimen from Gifu (Honshu), Japan, but is unidentifiable from the original description and illustrations. In order to clarify its status, this specimen (Type 11839, Museum of Comparative Zoology, Harvard) has been examined and the genitalia illustrated here (Fig. 2). This specimen lacks a head, but is otherwise complete and adequate for comparative study. The genitalic structures had been cleared previously and some of the appendages showed slight damage.

In describing Molanna falcata from Japan, Ulmer stated it was differentiated from $M$. moesta by darker colouring, by the presence of apical fork no. 5 (i.e. separation of $\mathrm{Cu}_{1 \mathrm{a}}$ and $\mathrm{Cu}_{1 \mathrm{~b}}$ ) in the hind wing, and by different genital appendages. I have not seen the holotype of $\boldsymbol{M}$. falcata, but Ulmer's illustrations and description seem clear, if somewhat diagrammatic.

Following comparison between the holotype of $M$. moesta and Ulmer's description of $M$. falcata, it is my conclusion that valid reasons do not now exist for the separation of the two, and therefore I am regarding $M$. falcata Ulmer as a junior synonym of $M$. moesta Banks. Evidence in support of this is as follows.

1) The genitalia of the holotype of $M$. falcata illustrated by Ulmer are almost identical with the holotype of $M$. moesta, even to the arched and rather narrow sclerotized plates of the tenth segment, as seen in lateral view. Although this same structure in dorsal view is shown by Ulmer (1908, fig. 10) to be a single plate with a deep apical incision, in the holotype of $M$. moesta it is composed of two separate plates. A similar situation is shown by Martynov (1910, fig. 17) for Siberian specimens which he assigns to $M$. falcata, and it seems likely that Ulmer's drawings are in error on this point. The degree of separation of these two plates appears to be variable in different figures, and it seems likely, too, that these differences are not significant at the species level. These Siberian specimens described by Martynov do in fact differ from the holotype of $M$. moesta by the somewhat enlarged tip of the sclerotized plates of the tenth segment, which bears enlarged spines. I concur with Martynov's assessment that these are but regional variants of a single species ranging through Japan and much of Siberia and the eastern U.S.S.R.

2) The separation of $\mathrm{Cu}_{1 \mathrm{a}}$ and $\mathrm{Cu}_{1 \mathrm{~b}}$ in the hind wing illustrated by Banks is based upon an incomplete and somewhat irregular development of $\mathrm{Cu}_{1 \mathrm{~b}}$ in the type specimen. This vein is evidently not separated in the type of $M$. falcata, but this does occur infrequently in Japanese specimens otherwise identifiable as $M$. moesta or $M$. falcata. The beginning of $\mathrm{Cu}_{1 \mathrm{~b}}$ is shown, in fact, in the hind wing of the Siberian specimens (Martynov 1910, 
fig. 16). This venational difference is therefore not significant at the species level. The other venational features of the holotype are in close agreement with the illustrations of $M$. falcata given by both Ulmer and Martynov.

3 ) In colour $M$. falcata is stated by Ulmer to be darker than $M$. moesta, and judging by the total wing expanse measurements, the type of $M$. moesta (length of fore wing $12 \mathrm{~mm}$.) is somewhat larger than $M$. falcata (total wingspread 21-23 mm.). The type specimen of $M$. moesta is light brown in colour. In view of the evidence already advanced, however, I would be inclined to interpret these differences of colour and size as variants within a single species- $M$. moesta. Lack of any means of distinguishing between the two has also been noted by Dr. Kuwayama (pers. comm.) in Japan.

Specimens available to me of the probable female of $M$. moesta have been examined, and there is a slight range of variation among them. One of these (Tokyo) is illustrated (Fig. 4) and its diagnostic characters compared with the following species under that heading.

Records available for this species under the two names $M$. moesta and falcata show it to be widely distributed in Japan and China and over much of eastern Siberia (Fischer 1964).

\section{Molanna paramoesta sp. $\mathbf{n}$.}

Represented by many specimens from a wide assortment of localities and habitats in the collections from India is a Molanna, which although very close to $M$. moesta in structure throughout, does show consistent differences in the male genitalia from $M$. moesta. In view of the fact, too, that morphological differences between the well-known species of Molanna are not great, it seems best to regard these specimens as representing a new species, at least until intermediates become known.

ADULTS. Length of fore wing: male 9-10 mm.; female 11-12 mm. Overall structure as in $M$. moesta and typical for the genus; overall colour medium brown. Apical segments of first legs medium brown, second and third legs and femora of first lighter. Fore wings medium brown with some lighter patches, more pronounced in the females. Venation as in M. moesta (Ulmer 1908, figs. 8, 9); hind wing with the groove in the anal part, regarded by Martynov (1910) as a character diagnostic for the subgenus Molanneria.

Male Genitalia (Fig. 1). In general structure similar to $M$. moesta (Fig. 2), but distinguished from that species by the inflated, hammer-like form of the paired sclerotized plates of the tenth segment in lateral view. In $M$. moesta this structure appears deflated and pendant. Comparison of the genitalic structures of the holotype specimens for these two species will indicate certain other differences, such as those in the superior (lateral) appendages of the tenth segment. These appear to be somewhat variable within each species and are not reliable diagnostic characters. The same is true of the degree of separation of the two sclerotized plates of the tenth segment in dorsal view, which more likely is determined by their position at death. 

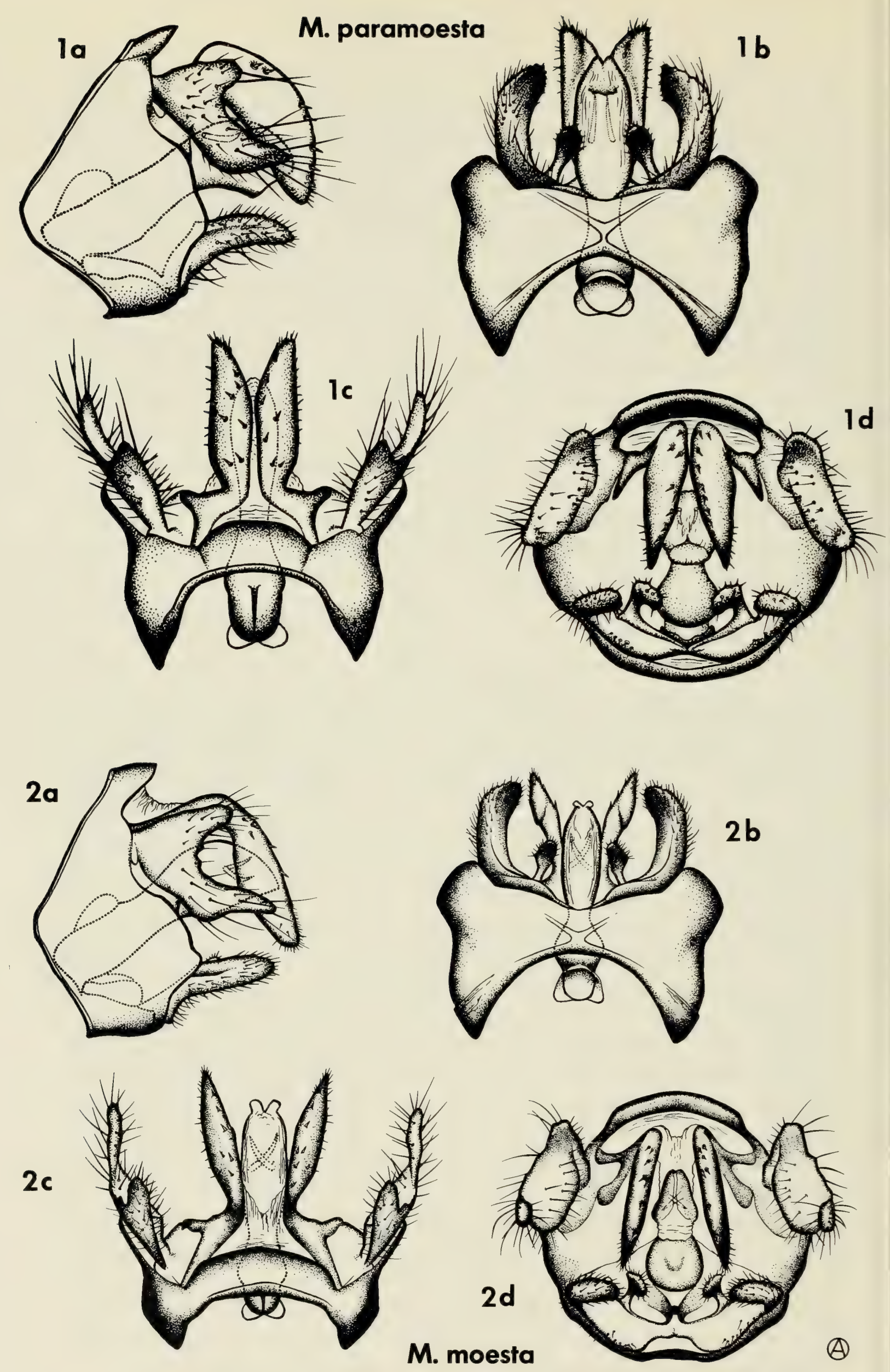

Figs. 1-2-Male genitalia in Molanna spp. 1. M. paramoesta sp. n. (holotype). 2. M. moesta Banks (holotype). $a$, lateral view; $b$, ventral view; $c$, dorsal view; $d$, caudal view. 
Female Genitalia (Fig. 3). Essentially similar to females assumed to represent M. moesta (Fig. 4; Tokyo, 24 May 1931; MCZ), but separable by a number of characters of degree. These appear to be subject to considerable variation in $M$. paramoesta, at least, where many specimens are available for study. Following is a summary of all of the characters which have been found to have some diagnostic significance. The specimens illustrated present all of these, but others do not. It appears that distinctions between the females of these two species have to be based on a consensus of the majority of the characters involved.
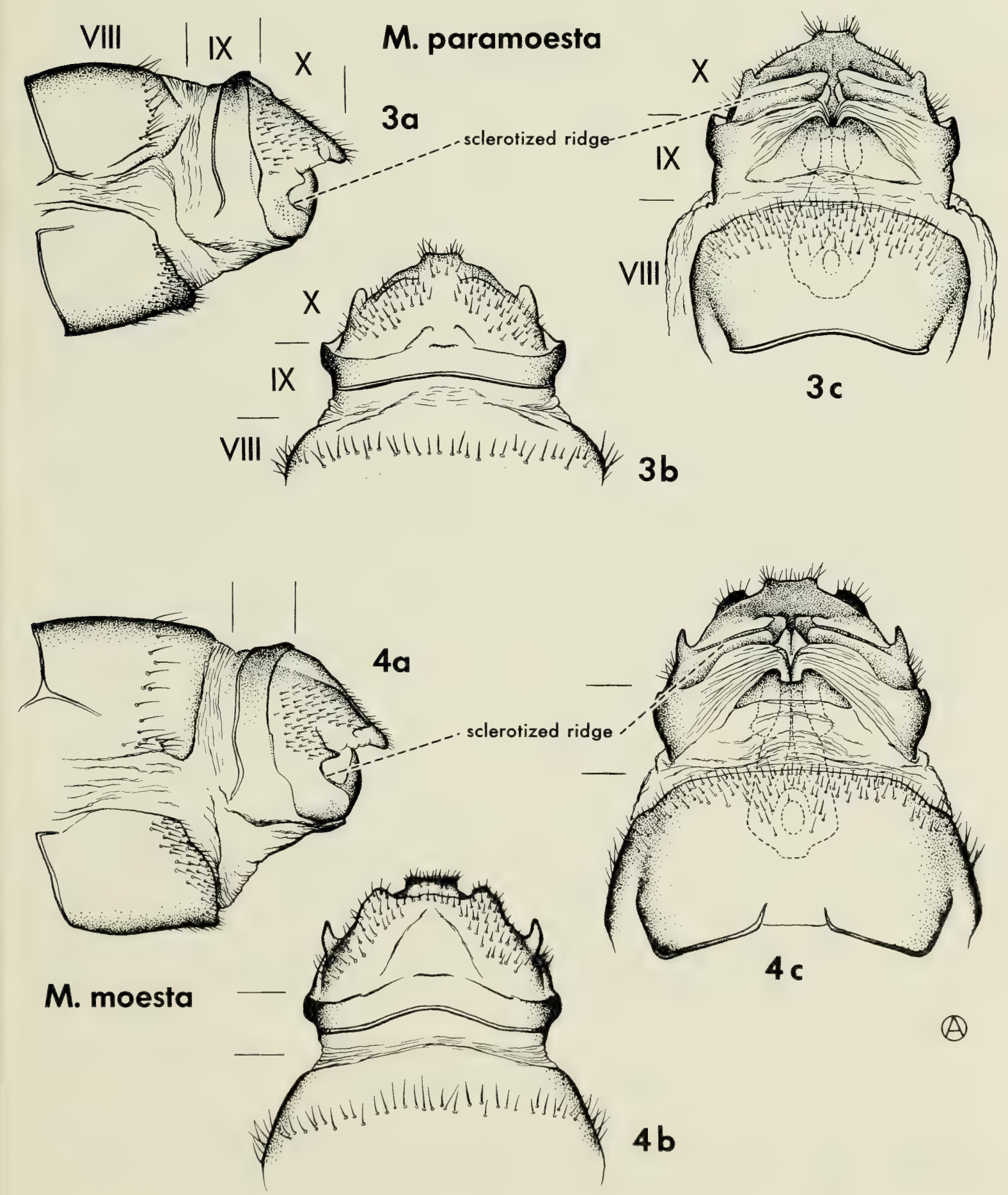

Figs. 3-4-Female genitalia in Molanna spp. 3. M. paramoesta sp. n.

4. M. moesta Banks. $a$, lateral view; $b$, dorsal view; $c$, ventral view. 
Segment IX of $M$. paramoesta in ventral view with a wide lateral collar or trough at the junction with the tenth segment; in $M$. moesta this trough is barely represented.

Segment X of $M$. paramoesta in ventral view with a pair of blunt posterolateral lobes and with a thinly sclerotized ridge running the length of the rectangular sclerite lying at each side of the genital opening; in dorsal view a pair of very low lobes lies mesad to the posterolateral lobes, and a short triangular median ridge has its base at the junction of segments IX and $\mathrm{X}$. Segment $\mathrm{X}$ of $M$. moesta in ventral view bears a pair of acute posterolateral lobes, and a heavily sclerotized ridge running the length of the rectangular sclerite lying at each side of the genital opening; in dorsal view a pair of fairly prominent lobes lies mesad to the posterolateral lobes, and a long triangular median ridge has its base at the junction of segments IX and X.

TYPES (all collected by F. Schmid, unless otherwise indicated). Holotype, male: INDIA, Madhya Pradesh: Satanwara, 1308 ft., 28 Nov. 1961. Para-

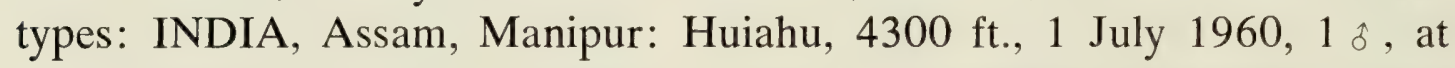
light; Khaiyang, 3200 ft., 18 June 1960, 1 \% , at light; Khamassom, 3900 ft., 24 June 1960, 1 o , at light; Khangairim, 4145 ft., 29 June 1960, 1 q, at light; Khanggoi, 4828 ft., 16 July 1960, 4 o 2 \%, at light; Mapum, 3300 ft., 12 June 1960, 1 of, at light; Sirohi, 4300 ft., 26 June 1960, 4 o ; Ukhrul, 6000 ft., 4 June 1960, $1 \hat{\delta}$, at light. Assam, United Jaintia and Khasi Hills: Demthring, 3800 ft., 16 April 1960, 1 \% at light; Mynso, $3500 \mathrm{ft}$., 20 April 1960, 2 o 1 o , at light; Nongjni, 3750 ft., 19 April 1960, 5 ô 5 o , at light; Shilliang Myntang, 3500 ft., 20 April 1960, 3 ô 2 \%, at light; Tadlaskein, $4250 \mathrm{ft}$, 17 April 1960, 2 \%; ibid., 1 o 1 \% , at light; Thangrain, 3000 ft., 22 April 1960, 1 o ; ibid., 1 o 1 \&, at light; Umlangshor, $4100 \mathrm{ft}$., 18 April 1960, 1 o 1 \%; ibid., 1 o 4 의, at light. Kerala: Maukut, 200 ft., 15 Jan. 1959, 2 \%, at light. Madhya Pradesh: Guna, 2000 ft., 7 Feb. 1959, 2 o 1 o , at light; Phalghat, 2000 ft., 6 Feb. 1959, 8 \& 7 \%, at light; Satanwara, 1308 ft., 28 Nov. 1961, 21 के 23 \% (type series); ibid., 6 Feb. 1962, 3 \% 1 \%, at light (topotypes); ibid., 8 Feb. 1962, 25 \& 5 o , at light (topotypes). Madras: Avalanche, $7200 \mathrm{ft}$., 28-30 Dec. 1958, 1 \%; Kodaikanal, 7400 ft., 5-12 Dec. 1958, 23 o 7 ㅇ ; Maraiyur, 3000 ft., 19 Dec. 1958, 5 o 1 \% , at light; Perumalmalai, $5000 \mathrm{ft}$., 7 Dec. 1961, 1 ô, at light. Mysore: Subrahmanya, 400 ft., 20 Jan. 1959, $1 \%$, at light. NEPAL: Bharatpur, 8 April 1957, 3 o 1 \% , E.I. Coher; Rapti Tal, Megouli, 300 m., 29 March-4 April 1962, $1 \hat{\delta}$, G. Ebert und H. Falkner (coll. Staatslg. Munchen); Shawani, 19 March 1957, 2 o , E.I. Coher.

The name given to this species is intended to emphasize its close similarity to $M$. moesta Banks.

Distribution. Known only from India and Nepal, but very widely distributed in India, from the Himalayas south to Kerala and Madras.

HABITAT AND BIOLOGY. The very wide variety of aquatic situations at which this species was collected will be treated in more detail by Dr. Schmid in a 
later publication. At this point it is sufficient to summarize these habitats as follows: artificial lakes with turbid water and marshy shores; large rivers with turbid water, little current, scattered rapid sections, gravel bed with algae; small streams in dense jungle; turbulent streams with clear water, sand and gravel beds; large slow rivers in bamboo jungle, clear water, sand bed. Collections of adults were made at elevations ranging from 200 to 7400 feet and throughout most of the year. This appears to be a widespread and common species of very broad ecological tolerance.

\section{Molanna crinita sp. $\mathbf{n}$.}

ADULT. Length of fore wing: male $11 \mathrm{~mm}$. Overall colour medium brown. Head of male (Fig. 6) with maxillary palpi very much elongated and covered with very thick and very long dark brown hairs; dorsum of head recessed around bases of antennae, remaining narrow area between the antennae with a dense pile of coarse hairs. Pronotum with two patches of extremely dense, coarse hairs; similar coarse hairs covering the median area of the mesonotum (Fig. 7). First legs darker than the others, but second and third tarsi slightly darker apically. Other structures typical for the genus. Wings medium brown, no distinctive markings evident; venation (Fig. 8) of fore wings as in $M$. moesta; hind wing narrow and elliptical, venation and anal area reduced more so than in $M$. moesta, a darkened fold extending the length of the wing, just in advance of the anal margin; anal margin of hind wing with a very densely packed band of thick hairs.

Male Genitalia (Fig. 5). Without close similarity to the genitalia of any known species. Ninth segment typical for the genus. Clasper scoop-like with the posterodorsal and posteroventral corners extended into prominent processes; a clavate mesal process arises from the base. Tenth segment with two flat sclerotized plates vertically appressed, the posteroventral corner of each extended into a linear process with an apical point turned sharply dorsad. Phallus with four stout spines in the invaginated endotheca.

Female unknown.

TYPE. Holotype, male: INDIA, Assam, North East Frontier Agency, Kameng Frontier Division: Chug, 7200 ft., 16 April 1961, F. Schmid. This single male holotype is the only specimen known.

The name given to this species refers to the remarkable development of long hair on the maxillary palpi and of thick hairs on areas of the head and thorax.

HABITAT AND BIOLOGY. This specimen was collected with a net along a small quiet stream in dense jungle.

\section{Molanna saetigera sp. $\mathbf{n}$.}

ADULT. Length of fore wing: male $9 \mathrm{~mm}$. Body medium brown overall; structure typical for the genus. Fore wings clothed with golden brown hairs; venation as in Fig. 9e; hind wing with a darkened fold running along the mid-line of the wing, and a patch of very long hairs immediately behind this line. 

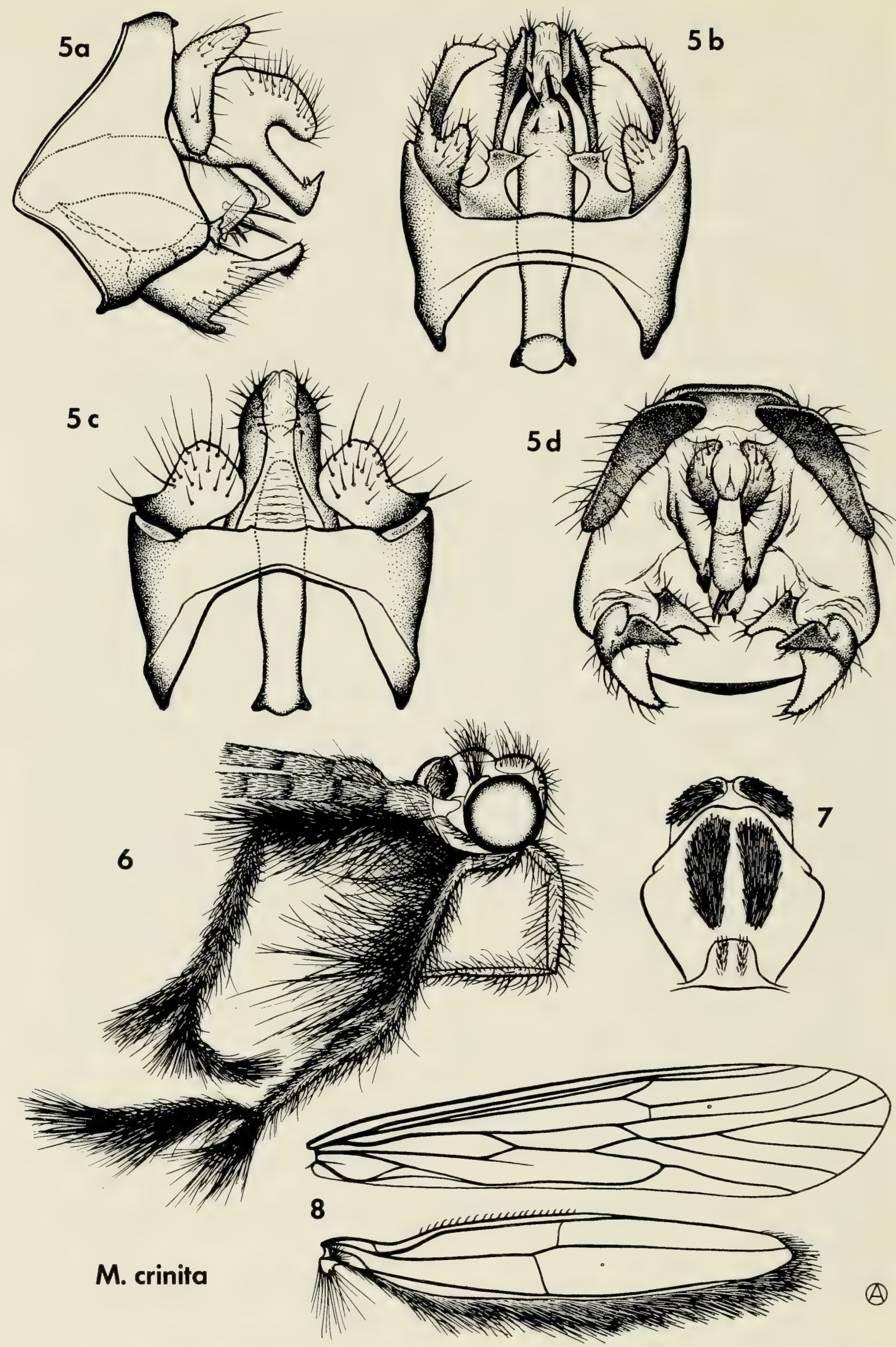

Figs. 5-8-Molanna crinita sp. n. 5. Male genitalia (holotype) : a, lateral view; $b$, ventral view; $c$, dorsal view; $d$, caudal view. 6 . Head of male. 7. Thorax of male, dorsal view. 8. Wings of male. 


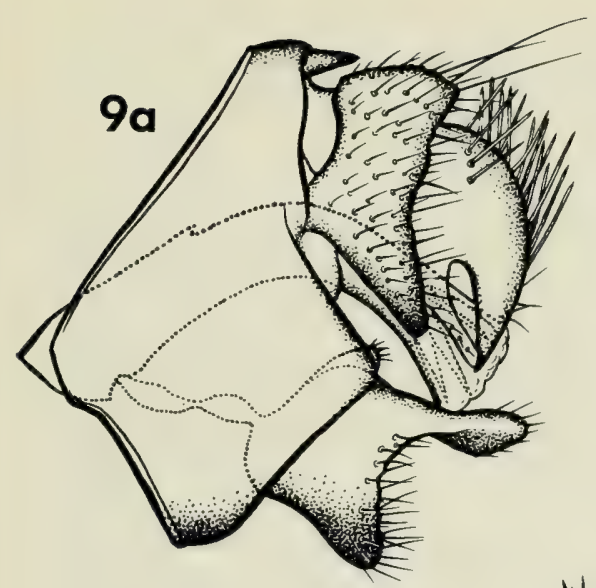

M. saetigera
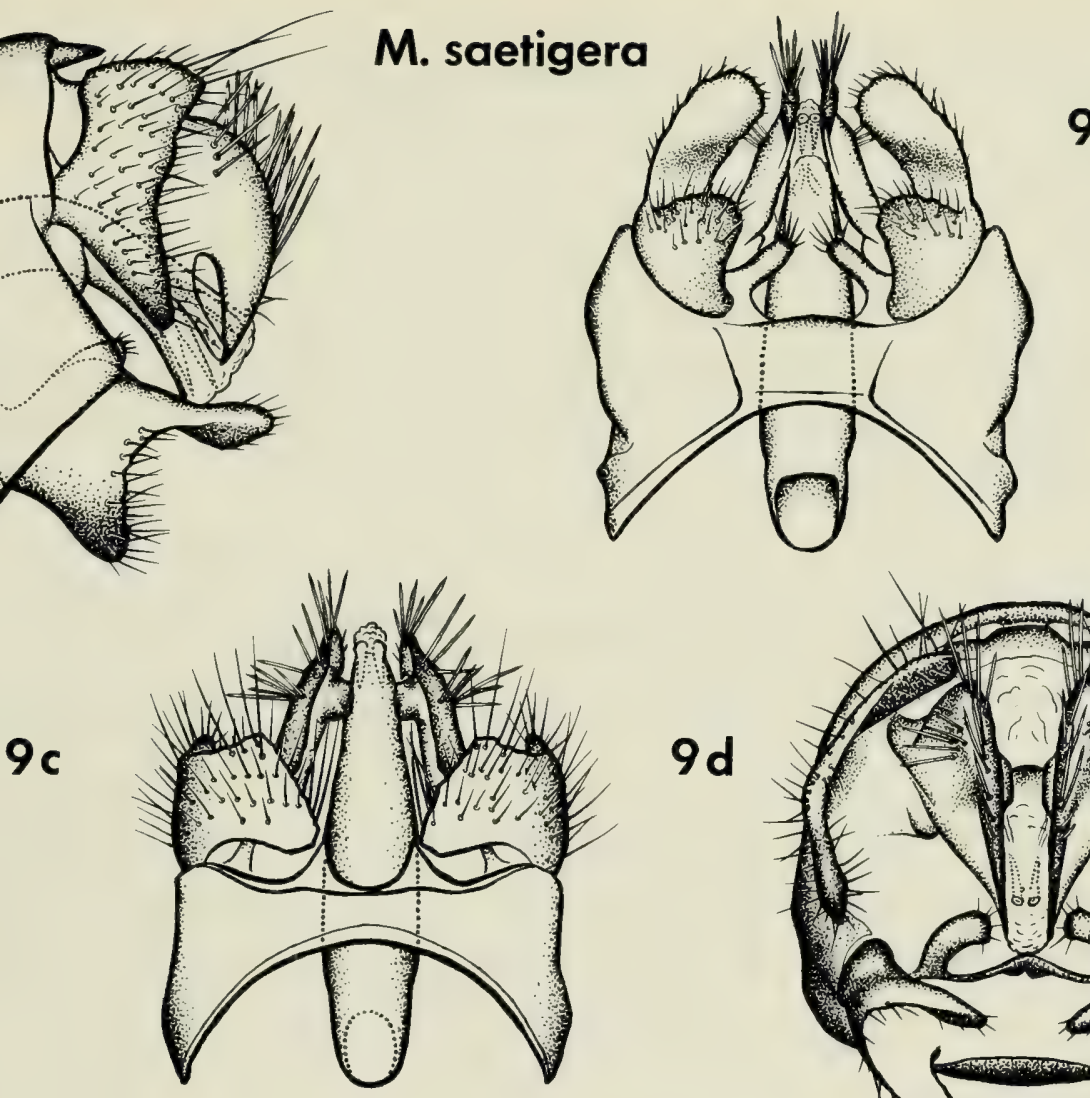

$9 \mathrm{~b}$
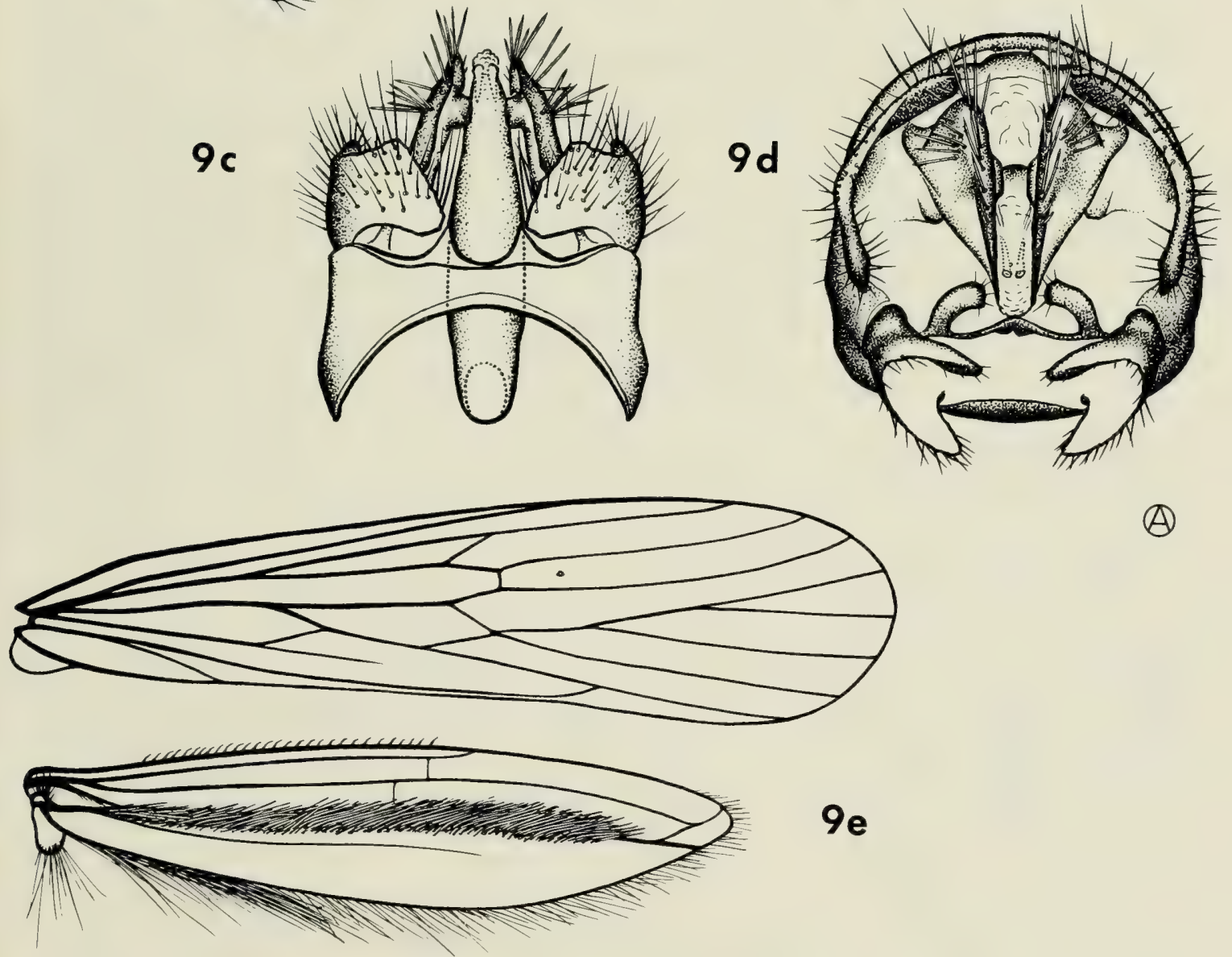

(A)

Fig. 9-Molanna saetigera sp. n. 9. Male (holotype): $a$, genitalia, lateral view; $b$, ventral view; $c$, dorsal view; $d$, caudal view; $e$, wings.

Male Genitalia (Fig. 9a-d). Without close similarity to the genitalia of any known species. Ninth segment generally typical for the genus; in dorsal view with a pair of short sharp points arising on the posterodorsal margin. Claspers scoop-shaped, the posterodorsal corner extended into a long process; a finger-like mesal process arising from the base. Tenth segment with two flat mesal plates vertically appressed; in lateral view each plate is rounded posteriorly, bearing many long stout spines, and terminating ventrally in a beak-like incision; in dorsal view each plate bears a short, thick mesal knob. Phallus strongly arched and bearing four stout spines in the invaginated endotheca.

Female unknown. 
TYPES. Holotype, male: INDIA, Assam, United Jaintia and Khasi Hills: Mawlang, 4000 ft., 12 April 1960, F. Schmid. Paratypes: same data as above, 2 ô.

The name given to this species refers to the long spines on the tenth segment.

HABIT AND BIOLOGY. These specimens were collected along two mediumsized, clear rivers with falls, the headwaters of the Wahrashi; two during the day and one at a light after dark.

\section{Molanna submarginalis McLachlan}

Molanna coreana Tsuda 1942, p. 231, figs. 5-7. NEW SYNONYMY.

Although no new material of this species is at hand, it has become apparent in the course of studying the Asian molannids that $M$. coreana, by the published description and illustrations, is not separable from M. submarginalis. In view of the fact that $M$. submarginalis has been recorded from the Amur River area (Martynov 1937), its presence in Korea is not surprising.

\section{Genus Molannodes McLachlan}

Up to the present time this has been the only other genus known to be represented in the molannid fauna of the northern hemisphere. The Eurasian representatives of this genus are now regarded as belonging to a single species, and study of material which has come recently to hand requires that the populations in extreme northwestern North America also be assigned to this species.

\section{Molannodes tinctus Zett.}

Molannodes bergi Ross 1952, p. 85, figs. 1-4. NEW SYNONYMY.

Comparison of both sexes in material of Molannodes from Alaska with specimens of $M$. tinctus from Finland and from the Amur River area of the U.S.S.R. shows that there is little, if any, difference among them. Examination of a series of specimens shows that the differences in the clasper of the male attributed to the Alaskan specimens are not concordant. The Finnish and Alaskan specimens are virtually identical, and exhibit some slight differences in size and male genitalia from the Amur specimens. The concept of a single species with minor regional variations over its enormous range seems to fit the available evidence.

Although the traditional spelling of this species name has been tincta, the International Code of Zoological Nomenclature (1961) takes the definitive position (Art. 30) that generic names ending in -odes are masculine, necessitating this emendation. 


\section{Genus Indomolannodes gen. $\mathbf{n}$.}

Type-species Indomolannodes decurvatus sp. n.

ADULTS. Basically similar to Molannodes, but distinguished by the structure of the male genitalia. Dorsum of head (Fig. 10) as in Molannodes, and distinct from Molanna, with a pair of elongate warts and a second smaller pair posterolaterad from these; a large triangular wart between the bases of the antennae. Maxillary palpi stout and long, with a dense hair covering, 5 -segmented in both sexes; the basal segment very short, the second segment twice the length of the basal, the three remaining segments each approximately twice the length of the second segment. Antennae stout, with a dense hair covering, slightly longer than the insect itself. Pronotum (Fig. 10) different in the sexes, as in Molannodes, the females with two pairs of rounded warts, the males with one; the median warts in the male replaced by a pair of membranous pouches. Mesonotum and metanotum typical for the family, without conspicuous warts, the mesoscutellum swollen and uniformly covered with short hairs. Legs with a dense covering of short hairs; spurs well developed 2, 4, 4; spines black and well developed. Wing shape (Figs. 16, 17) as in Molannodes, and distinct from Molanna in not being curled around the body and in having $\mathbf{R}_{2+3}$ separate from $\mathbf{R}_{1}$ in the fore wing; a row of coupling hooks along the costal margin of the hind wing, typical for the family. Venation generally as in Molannodes, but distinct in that $M_{1}$ and $M_{2}$ are united in the fore wing of the male, but
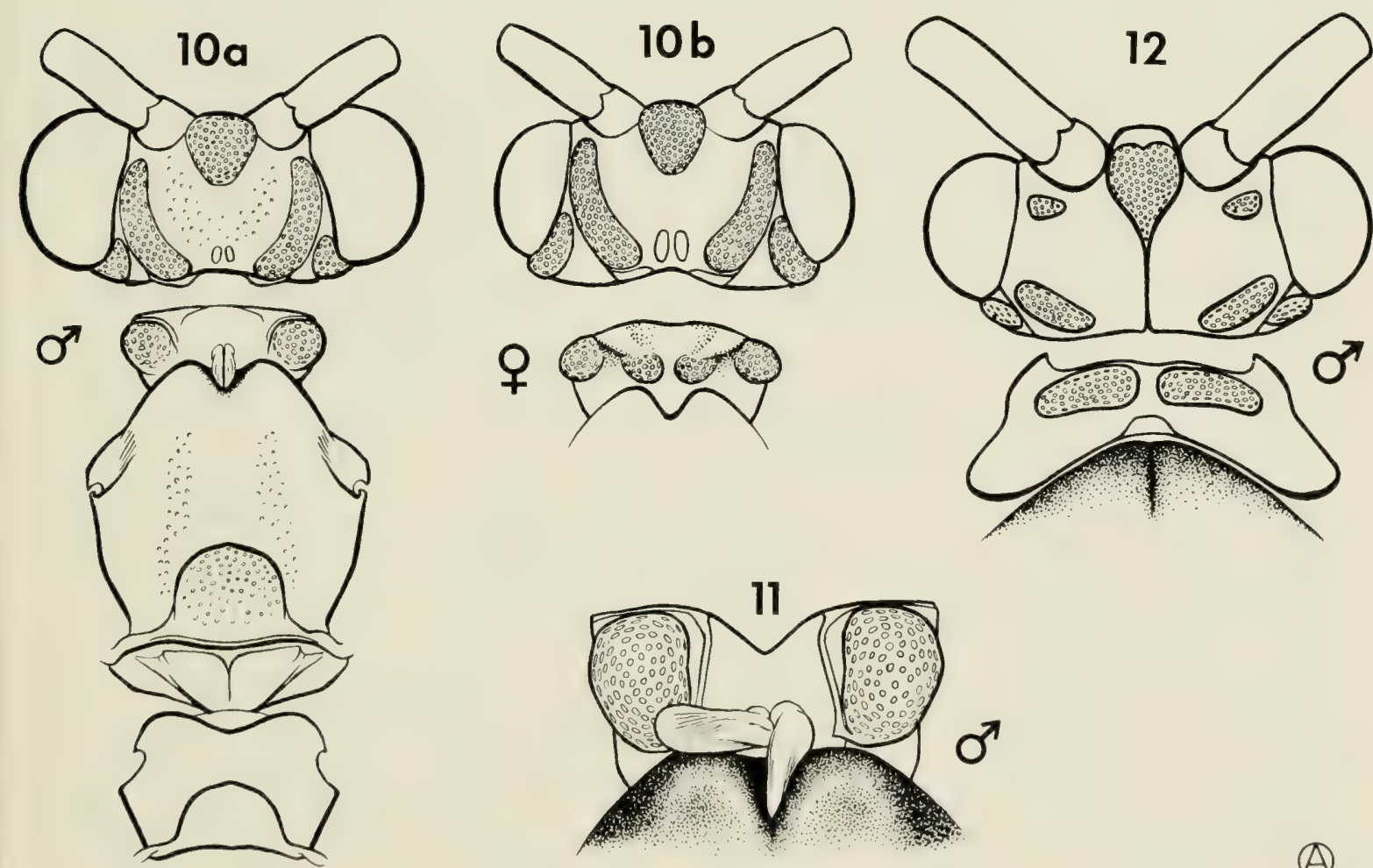

Figs. 10-12-10. Indomolannodes excavatus sp. n.: a, head and thorax of male, dorsal view; $b$, head and pronotum of female, dorsal view. 11. Molannodes tinctus Zett., pronotum and part of mesonotum, male, dorsal view. 12. Molanna flavicornis Banks, head, pronotum and part of mesonotum, male, dorsal view. 
separate in the female, with the result that the venation of the sexes is different in Indomolannodes (although in one species, I. excavatus, the venation is the same in the two sexes as it is in Molannodes).

Male Genitalia (Fig. 13). Characterized by a highly complex development of all the component parts represented in Molannodes. Ninth segment rather narrow throughout, the dorsum exposed in the normal way, but the entire ventral area, along with approximately one-half the width of the lateral area, recessed into the eighth segment; the posteroventral margin of the sternum of segment VIII rolled dorsad and developed into prominent points or lobes. Claspers composed of two distinct branches: a ventral branch which in lateral view is distinctly hook-shaped; and a dorsal branch which usually takes the form of a slender finger-like appendage. Tenth segment composed of three parts: a dorsomedian roof-like plate; a lateral pair of prominent superior appendages; and a pair of mesal appendages, usually extended into conspicuous lobes or processes, which may be homologous with the intermediate appendages (sensu Nielsen 1957). Phallus composed of a short, tubular, sclerotized phallotheca, from within which there can be everted a membranous endotheca bearing a dorsal extensile arm terminating in one or two bristle-covered lobes, and also other patches of setae; the ejaculatory duct and phallotremal sclerite can be seen within the endotheca in certain preparations (Figs. 14e, 15e). A heavily sclerotized, median piece lies ventrad of the endotheca.

Female Genitalia (Fig. 22). Of the same basic structure as in Molannodes. Sternum of the eighth segment forming a prominent posteroventral lip which is variously excised in different species. A semi-membranous plate with many fine linear striations lies at each side of the genital opening. Tenth segment forms a prominent roof-like plate extending above the genital opening; the apical margin of this plate is variously developed in different species.

IMMATURE STAGES. No material is available for this genus.

HABITAT AND BIOLOGY. Adults have been collected in large numbers, largely at lights but also by net, in the immediate vicinity of rivers and streams of mountainous, wooded country.

DISTRIBUTION. This genus is known from a long segment of the Himalayan range, the hills situated south of the Brahmaputra valley in Assam and from northeastern Burma.

REMARKS. The reason for the pronotal warts in Indomolannodes (Fig. 10) and Molannodes (Fig. 11), but not Molanna (Fig. 12), comprising two pairs in the females and one pair in the males, appears to be that in the males the mesal pair is modified into a pair of whitish membranous pouches. These appear to be capable of sufficient extension that as two ribbon-like strands they can be passed into a slit-like concavity in the cleavage depression at the anterior-most point of the mesonotum. In view of the fact that these structures are totally absent in the females, it seems clear that they are associated in some way with sexual attraction by the males. The structure of the membranous pouches is not clear in specimens 

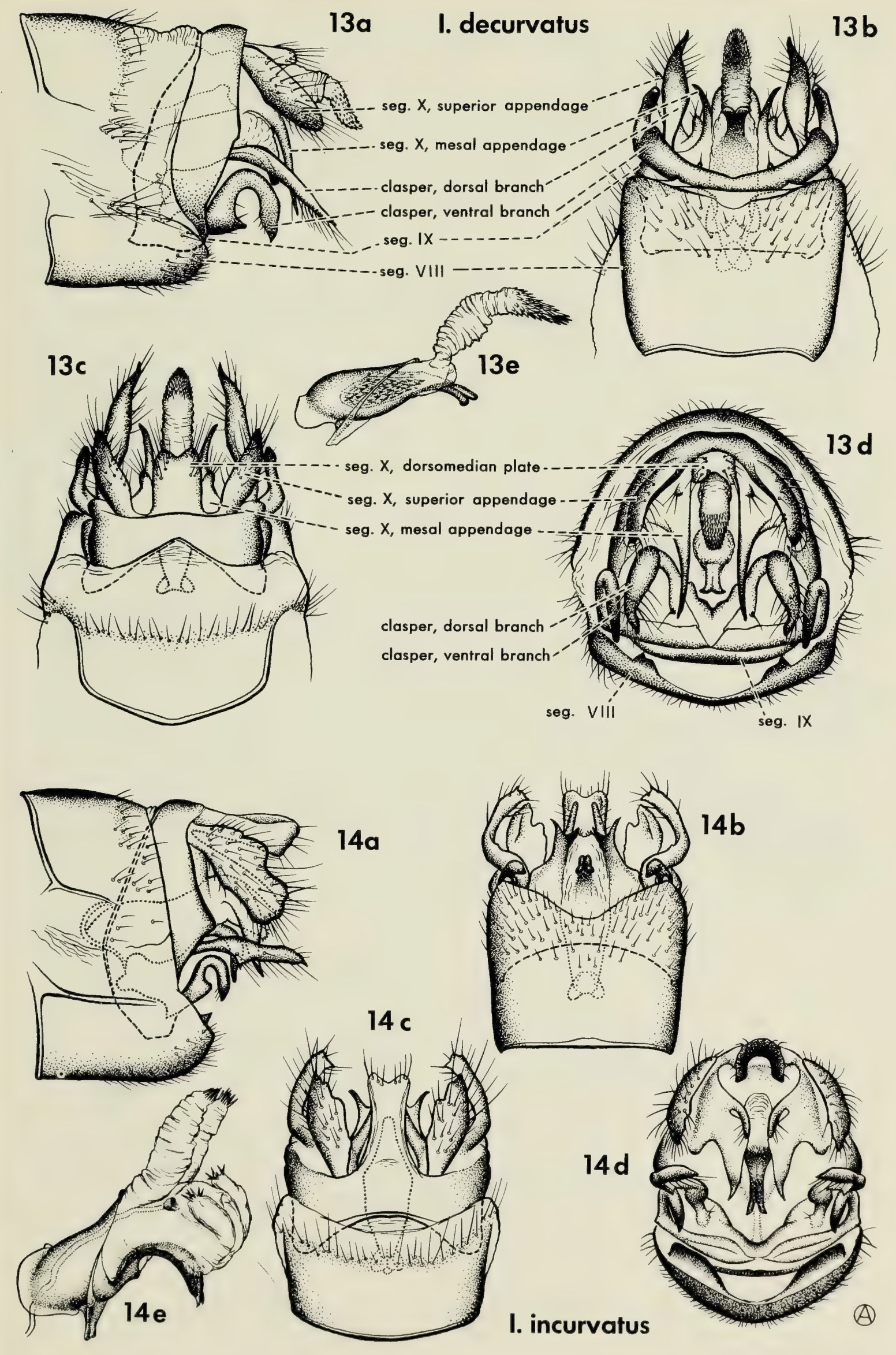

Figs. 13-14-Male genitalia in Indomolannodes spp. 13. I. decurvatus sp. n. (holotype). 14. I. incurvatus sp. n. (holotype). a, lateral view; $b$, ventral view; $c$, dorsal view; $d$, caudal view; $e$, phallus (from paratypes). 

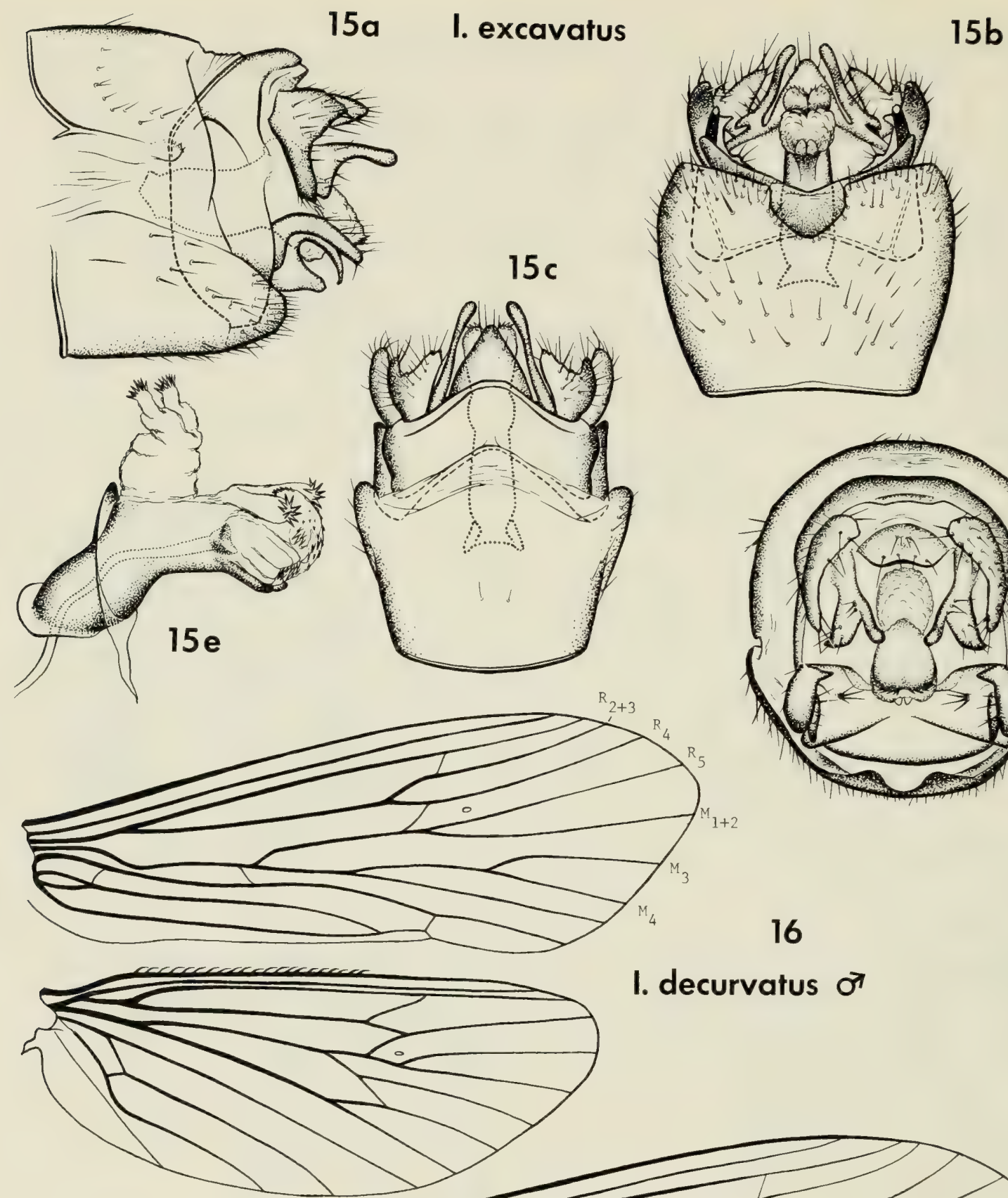

\section{I. decurvatus o7}

17

I. decurvatus 우
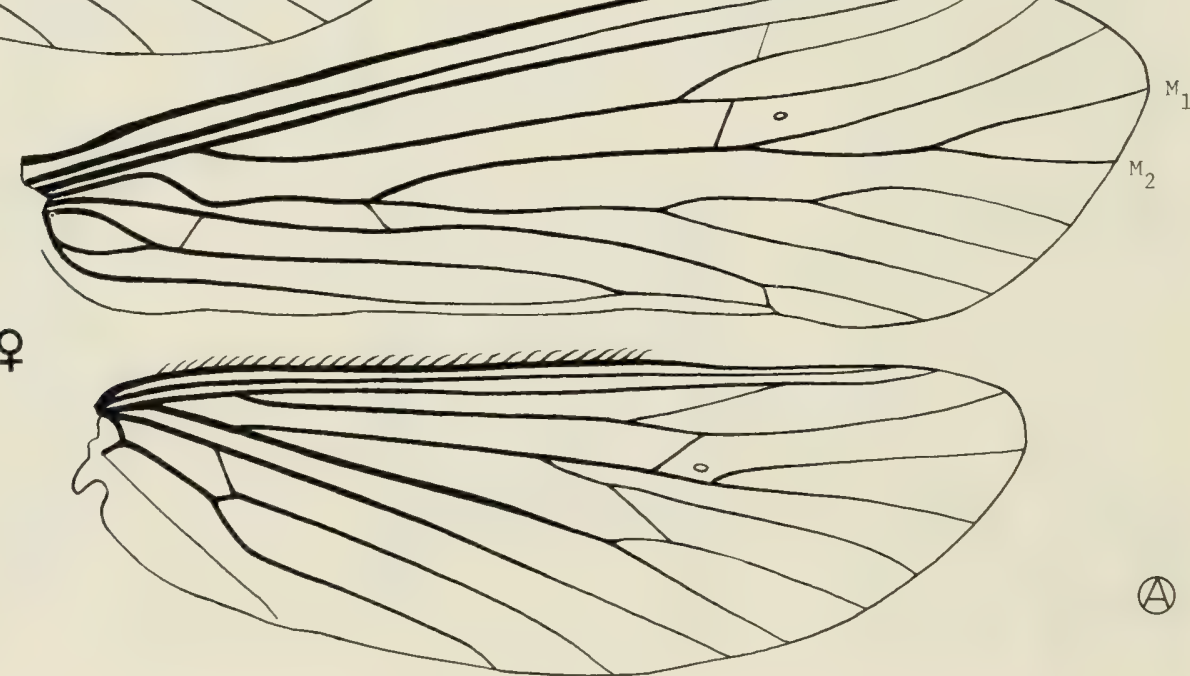

Figs. 15-17-15. Indomolannodes excavatus sp. n., male genitalia (holotype): $a$, lateral view; $b$, ventral view; $c$, dorsal view; $d$, caudal view; $e$, phallus (from paratype). 16. I. decurvatus sp. n., wings of male. 17. I. decurvatus sp. n., wings of female. 
of Indomolannodes available to me, which are dried, but in Molannodes, where alcoholic specimens are available, the hard parts of the pronotum and mesonotum are identical, and the membranous pouches (Fig. 11) can be seen in detail.

The name given to this genus is intended to convey the concept of a group related to Molannodes, with distribution centred in India. As indicated under the preceding genus, the name is of masculine gender.

\section{Key to the Species of Indomolannodes}

1. Males

Females

2. Mesal appendages of tenth segment in the form of broad, leaflike expansions (Figs. 13, 14)

Mesal appendages of tenth segment not expanded and leaf-like (Figs. 18, 19)

3. Dorsal branch of the clasper with its apex curved strongly ventrad; mesal appendage of the tenth segment with a very long, slender, pointed, ventral process and a small dorsal protuberance (Fig. 13)

I. decurvatus

Dorsal branch of the clasper with its apex curved strongly mesad; mesal appendage of the tenth segment with a broader, pointed, ventral process and a finger-like dorsal process (Fig. 14)

\section{I. incurvatus}

4. Mesal appendages of tenth segment with long and very slender processes; posterior margin of the eighth sternum without a prominent median notch (Figs. 18, 19)

Mesal appendages of tenth segment without long, slender processes; posterior margin of the eighth sternum with a prominent median notch (Fig. 15)

I. excavatus

5. Posterior margin of the eighth sternum extended dorsad into a lateral pair of prominent vertical lobes, each with an apical horizontal lip; dorsal branch of the clasper finger-like in lateral view (Fig. 18)

Posterior margin of the eighth sternum extended caudad into a lateral pair of pointed lobes; dorsal branch of the clasper widened in lateral view, with a slender terminal process (Fig. 19)

6. Tenth segment extended into an elongate, compressed median process (Figs. 23, 24)

Tenth segment without a compressed median process (Figs. 20-22)

I. falcifer

I. comans

7. Median process of tenth segment of uniform depth in lateral view (Fig. 24)

\section{I. incurvatus}

Median process of tenth segment with a pronounced knob at the apex in lateral view (Fig. 23)

I. comans

8. Posterior margin of eighth sternum in ventral view entire; apical margin of tenth segment in ventral view rounded and somewhat truncate (Fig. 22)

I. excavatus

Posterior margin of eighth sternum with a prominent mesal notch (Figs. 20, 21) 
9. Posterior margin of eighth sternum with mesal notch wide; apical margin of tenth segment evenly rounded in ventral view (Fig. 21)

\section{I. decurvatus}

Posterior margin of eighth sternum with mesal notch much narrower and somewhat V-shaped; apical margin of tenth segment roughly trilobate in ventral view (Fig. 20)

I. falcifer

\section{Indomolannodes decurvatus sp. $\mathbf{n}$.}

ADULTS. Length of fore wing: male $6 \mathrm{~mm}$.; female $7 \mathrm{~mm}$. Overall structure typical for the genus; medium brown in colour. Antennae with very narrow light alternating bands. Fore wings uniform medium brown, thickly covered with hairs. Venation (Figs. 16, 17) different in the sexes, with $\mathrm{M}_{1}$ and $\mathrm{M}_{2}$ united (usually) in the fore wing of the male but separated in the female.

This species is most readily distinguished by characters of the male and female genitalia.

Male Genitalia (Fig. 13). Most closely resembling I. incurvatus, but clearly distinguished by characters given in the key. Ninth segment narrow on the extreme dorsum, but of fairly uniform width elsewhere. Posterior margin of the eighth sternum rounded dorsad and extended into a pair of small pointed lobes. Ventral branch of the clasper shaped like a large hook in lateral view; dorsal branch of the clasper in the form of a long slender process which curves ventrad. Tenth segment with dorsomedian plate short and parallel-sided; superior appendages simple lobes; mesal appendages enlarged and leaf-like with a very long and slender ventral process and a small dorsal protuberance. Phallus with a sclerotized, bifurcate ventral piece and an extensile, bristle-tipped dorsal appendage (illustrated with the endotheca invaginated because efforts to evert it in several specimens met with no success).

Female Genitalia (Fig. 21). Most closely resembling I. falcifer, but distinguished by characters given in the key. Posterior margin of the eighth sternum with a wide, rounded excision in ventral view. Apical margin of the tenth segment extended into an evenly rounded lobe.

TYPES (all collected by F. Schmid, unless otherwise indicated). Holotype, male: INDIA, Assam, Manipur: Chingsao, 4500 ft., 15 June 1960. Paratypes: INDIA, Assam, Manipur: Chingsao, $4500 \mathrm{ft}$, 15 June 1960, 7 ô 11 q (type series); ibid., 5400 ft., 13 June 1960, 3 q, at light; ibid., 3800 ft., 14 June 1960, 3 o 11 o, at light; Langdang, 5300 ft., 5 June 1960, 2 of 1 o , at light; Mattiyang, $2800 \mathrm{ft}$., 17 June 1960, 1 우, at light; Sirohi Kashong, $6200 \mathrm{ft} ., 10$ June 1960, 2 o 1 \%, at light. BURMA: Kambaiti (N.E. Burma), $7000 \mathrm{ft} ., 1$ June 1934, 1 o (Swedish Exp. to Burma; coll. Riksmuseum, Stockholm).

The name given to this species refers to the ventrally directed dorsal branches of the claspers.

Distribution. Known only from Manipur (Assam) and northeast Burma. 
HABITAT AND BIOLOGY. All the available material of this species bearing information concerning habitat was collected at lights, but in every case the lights were located beside turbulent streams in densely wooded mountainous areas, at elevations ranging from 2800 to 7000 feet. Adults were collected only in June, occasionally along with $I$. falcifer.

\section{Indomolannodes incurvatus sp. $\mathbf{n}$.}

ADULTS. Length of fore wing: males 6-7 mm.; females 8-9 mm. Overall structure typical for the genus; somewhat lighter brown in colour than the other species. Head with light hairs; antennae with light alternating bands. Fore wings with light hairs mixed with the brown, apparently more so in the males, but the somewhat rubbed condition of the wings in most of the specimens make this uncertain. Venation as in I. decurvatus, different in the sexes with $M_{1}$ and $M_{2}$ united in the fore wing of the male but separated in the female.

This species is most readily distinguished by characters of the male and female genitalia.

Male Genitalia (Fig. 14). Most closely resembling I. decurvatus, but clearly distinguished by characters given in the key. Ninth segment narrowed at the dorsal and ventral extremities, wider laterally, with a prominent point arising mid-laterally from the posterior margin. Posterior margin of the eighth sternum rounded dorsad to form a pair of smoothly margined lobes. Ventral branch of the clasper hook-shaped in lateral view as in I. decurvatus, but the hook much smaller (there is some variation in the size of the hook); dorsal branch of the clasper in the form of a long slender process with a ventral spur, the process curving sharply mesad, instead of ventrad as in $I$. decurvatus. Tenth segment with dorsomedian plate long and narrow, the lateral margins somewhat deflated; superior appendages rather more expanded than in $I$. decurvatus, their margins irregular; mesal appendages enlarged and leaf-like as in I. decurvatus, but with a broader, pointed ventral process and a finger-like dorsal process; in some specimens (Pauri Garhwal: Tungnath) this dorsal process is much longer than illustrated. Phallus basically typical for the genus, distinct from I. decurvatus in having a stouter ventral piece and in having two arms on the extensile appendage, each with a bristle-tipped lobe.

Female Genitalia (Fig. 24). Resembling most closely I. comans, but distinguished by characters given in the key. Posterior margin of the eighth sternum slightly excavate in ventral view. Tenth segment developed into a prominent median process, the lateral margins sharply compressed, the apex simple.

TYPES (all collected by F. Schmid). Holotype, male: INDIA, Assam, North East Frontier Agency, Kameng Frontier Division: Shergaon, 6500 ft., 9 May 1961. Paratypes: INDIA, Assam, North East Frontier Agency, Kameng Frontier Division: Bilo La, 6000 ft., 10 June 1961, 1 \% ; Bomdi La, 8800 ft., 13-21 June 1961, 1 ㅇ ; Dirang Dzong, 6500 ft., 21-22 July 1961, 1 \&, at light; Kelang, 6000 ft., 2 July 1961, 2 o 1 \%, at light; Mosh- 
ing, 6800 ft., 4-7 Sept. 1961, 1 \& , at light; ibid., 7200 ft., 8-10 Sept. 1961, 1 o , at light; Nafra, 4000 ft., 26 June 1961, 2 ; Nakhu, 4500 ft., 3 July 1961, 2 s, at light; ibid., 4800 ft., 4 July 1961, 2 오, at light; Nizong, 4800 ft., 27 June 1961, 1 ô ; Nyukmadong, 6600 ft., 1 Aug. 1961, 1 o, at light; Rahung, 7000 ft., 16 Aug. 1961, 1 의, at light; ibid., 6500 ft., 17 July 1961, 2 o 3 of, at light; ibid., 7300 ft., 17 Aug. 1961, 1 o 1 오, at light; Shergaon, $6800 \mathrm{ft} ., 1$ Sept. 1961, 1 ô, at light; Talung Dzong, 7800 ft., 13-14 Sept. 1961, 1 , at light. INDIA, Pauri Garhwal: Khumyara, 4500 ft., 3-4 May 1961, 1 ô ; Tungnath, 7500 ft., 1 June 1961, 1 ô.

The name given to this species refers to the mesally directed dorsal branches of the claspers.

Distribution. Known in the Himalayas from Garhwal (west of Nepal) to Kameng (northern Assam, east of Bhutan).

HABITAT AND BIOLOGY. The material available all comes irom the vicinity of turbulent streams in densely wooded mountainous areas, at elevations ranging from 4500 to 8800 feet. Adults were collected from May to September.

\section{Indomolannodes excavatus sp. $\mathbf{n}$.}

ADULTS. Length of fore wing: male 6-7 mm.; female 7-8 mm. Overall structure typical for the genus; medium brown in colour; antennae with narrow, light, alternating bands; head and thorax as in Fig. 10. Fore wings uniform medium brown in colour with a dense coating of hairs; venation unique among the five species of Indomolannodes here described because in the fore wings of both sexes $\mathbf{M}_{1}$ and $\mathbf{M}_{2}$ are separated, as they are in Molannodes.

This species is most readily distinguished by characters of the male and female genitalia.

Male Genitalia (Fig. 15). Generally resembling $I$. decurvatus and incurvatus, but abundantly distinct by characters given in the key. Ninth segment narrowed dorsally and ventrally, of fairly uniform width laterally. Posteroventral edge of the eighth segment with a rounded median excavation, the two corners of this excavation somewhat enlarged and rolled dorsad. Dorsal and ventral branches of the clasper separated only near their apices; dorsal branch forming a curved finger-like appendage in lateral view, in caudal view a sharp mesal spur is apparent; ventral branch forming a prominent hook in lateral view. Tenth segment with dorsomedian plate triangular and the lateral edges convex in dorsal view; superior appendages with a prominent ventral extension; mesal appendages with a slender elongate dorsocaudal process. Phallus essentially as in I. incurvatus but the median sclerotized piece short.

Female Genitalia (Fig. 22). Most closely resembling I. decurvatus, but distinguished by characters given in the key. Eighth sternum with the posterior margin entire. Tenth segment in ventral view evenly rounded laterally, the apical margin somewhat truncate. 
TYPES (all collected by F. Schmid). Holotype, male: INDIA, Assam, Manipur: Poi, 4200 ft., 4 July 1960. Paratypes: INDIA, Assam, Manipur: Chingai, 4400 ft., 8 July 1960, 1 ô , at light; Huiahu, 3800 ft., 3 July 1960, $1 \hat{\delta}$, at light; Khamassom, $3900 \mathrm{ft} ., 24$ June 1960, 2 s , at light; Khanggoi, 4828 ft., 16 July 1960, 1 \%, at light; Longbi Khulen, 4500 ft., 30 June 1960, 3 o 1 ㅇ, at light; Mapum, 3300 ft., 12 June 1960, 1 o 2 o , at light; Poi, 4 July 1960, 1 \% ; ibid., 4200 ft., 4 July 1960, 6 o 4 \&. (type series); Sirohi, 4300 ft., 26 June 1960, 6 \& 8 ㅇ, at light; ibid., 4100 ft., 9 July 1960, 3 o 9 우, at light.

The name given to this species refers to the prominent mesal excavation on the eighth sternum of the male.

Distribution. Known only from Manipur in Assam.

HABITAT AND BIOLOGY. The data available indicate that this species lives at somewhat lower elevations, 3300 to 4800 feet, than most of the others. The collections were made generally in the vicinity of somewhat larger streams, and often around rice fields. Adults were collected only in June and July. This species was taken along with Molanna paramoesta Wiggins at several locations.

\section{Indomolannodes falcifer sp. $\mathbf{n}$.}

ADULTS. Length of fore wing: male 7-8 mm.; female $8-9 \mathrm{~mm}$. Overall structure typical for the genus; medium brown in colour; antennae with light, narrow, alternating bands. Fore wings with a dense coating of hairs, medium brown in colour with indefinite light yellowish patches in the apical area, at the arculus and around the bifurcation of Rs. Venation as in I. decurvatus.

This species is readily distinguished by characters of the male and female genitalia.

Male Genitalia (Fig. 18). Most closely resembling I. comans, but distinguished most readily by characters given in the key. Ninth segment very narrow dorsally, the lateral portion broadest above the mid-line, and tapering ventrad from that point. Posterior margin of the eighth sternum extended dorsad into a lateral pair of prominent vertical lobes, each with an apical horizontal lip; in caudal view a very wide rounded concavity lies between the two vertical lobes. Ventral branch of the clasper in the form of a heavily sclerotized, downturned spike; dorsal branch of the clasper slender and finger-like, bearing a mesal pair of short thin processes. Tenth segment with dorsomedian plate triangular, the lateral margins concave in dorsal view; superior appendages somewhat mitten-like in shape, the broadest part ventrad; mesal appendages each with an extremely slender sickle-like process, each frequently crossing the other behind the phallus, and with a flat clavate process arising separately at the base. Phallus of the same basic structure as the other species in the genus, but with a pair of slender sclerites in the endotheca; extensile appendage armed with curious truncate bristles. 


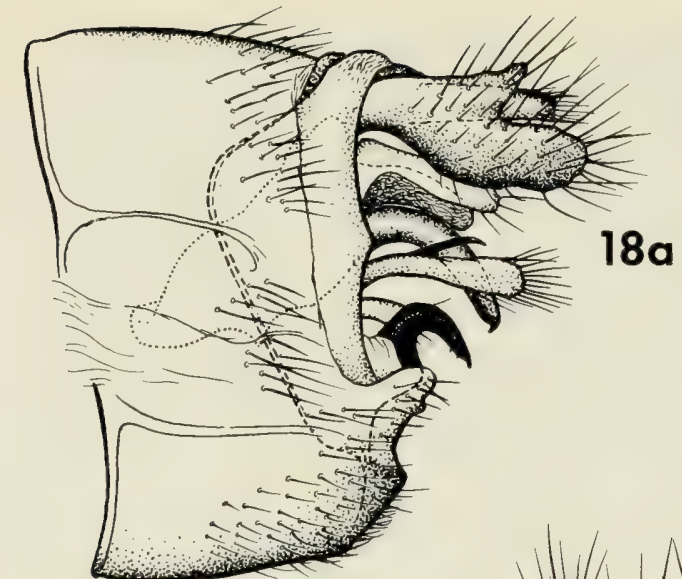

I. falcifer
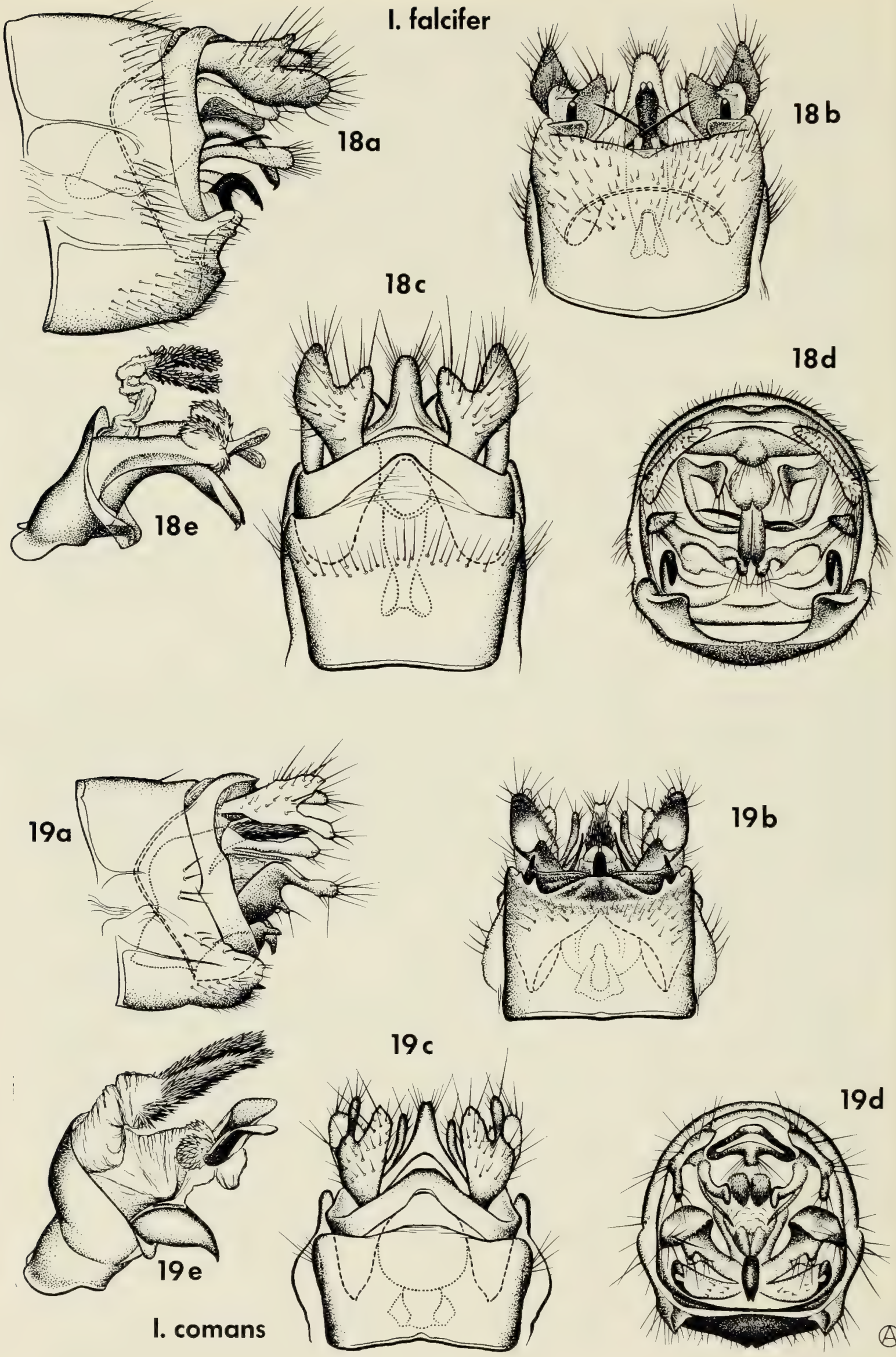

Figs. 18-19-Male genitalia in Indomolannodes spp. 18. I. falcifer sp. n. (holotype). 19. I. comans sp. n. (holotype). $a$, lateral view; $b$, ventral view; $c$, dorsal view; $d$, caudal view; $e$, phallus (from paratypes). 
Female Genitalia (Fig. 20). Resembling most closely I. decurvatus, but distinguished by characters given in the key. Posterior margin of the eighth sternum with a narrow $\mathrm{V}$-shaped median notch. Apical margin of the tenth segment roughly trilobate in ventral view.

TYPES (all collected by F. Schmid). Holotype, male: INDIA, Assam, United Jaintia and Khasi Hills: Rumkheng, 4500 ft., 24 March 1960. Paratypes: INDIA, Assam, Manipur: Chingsao, 3800 ft., 14 June 1960, 3 o , at light; Hkayam Boum, 8000 ft., 20-23 June 1960, 2 ㅇ, at light; Huiahu, 5000 ft., 2 July 1960, 1 o 1 s , at light; Khopum, 2500 ft., 27 May 1960, 1 of 3 o , at light; Mattiyang, $2800 \mathrm{ft}$., 17 June 1960, 2 의, at light; Sirohi Kashong, 6200 ft., 10 June 1960, 3 ô , at light; ibid., $7000 \mathrm{ft}$., 6-7 June 1960, 1 of 2 \% , at light; ibid., 7000 ft., 11-13 July 1960, 1 o , at light; Tairenpokpi, 4000 ft., 31 May 1960, 1 , at light. INDIA, Assam, United Jaintia and Khasi Hills: Jarain, $2800 \mathrm{ft}$, 13 April 1960, 1 o ; Laitlyngkot, 5000 ft., 15 March 1960, 1 क 2 o , at light; Rumkheng, $4500 \mathrm{ft}$., 24 March 1960, 3 o 1 ㅇ, at light (type series); ibid., 20-23 March 1960, 1 ㅇ (topotype); Serrarim, 5800 ft., 3 Oct. 1960, 1 \% ; Syntung, 4000 ft., 11 April 1960, 1 o , at light.

The name given to this species means sickle-bearing, in reference to the curved blades on the mesal appendages of the tenth segment.

Distribution. Known from Manipur and the Khasi Hills in Assam.

HABITAT AND BIOLOGY. Records for adults of this species range from elevations of 2500 to 8000 feet, and from March to October. Collections of adults were made in the vicinity of turbulent streams in densely wooded areas (where they were taken along with $I$. decurvatus at some localities), and medium-sized rivers.

\section{Indomolannodes comans sp. $\mathbf{n}$.}

ADULTS. Length of fore wing: male 6-7 mm.; female 7-8 mm. Medium brown in colour; antennae with light, narrow, alternating bands; overall structure typical for the genus, but distinctive in having the femora, and especially the tibiae and the tarsi of the fore legs of the male densely clothed with long whitish hairs; the hairs on the warts of the head and of the pronotum are unusually long and dense as well. Fore wings with yellowish patches on a medium brown hairy covering, largely in the apical half, but with two larger patches in the basal portion. Venation as in I. decurvatus.

This species is most readily distinguished by characters of the male and female genitalia.

Male Genitalia (Fig. 19). Most closely resembling I. falcifer, but distinguished most readily by characters given in the key. Ninth segment as in I. falcifer, very narrow dorsally, the lateral portion broadest above the mid-line, and tapering ventrad from that point. Posterior margin of the eighth sternum rounded dorsad into a heavily sclerotized caudal plate, the lateral corners of which are extended caudad into a pair of bidentate lobes. 

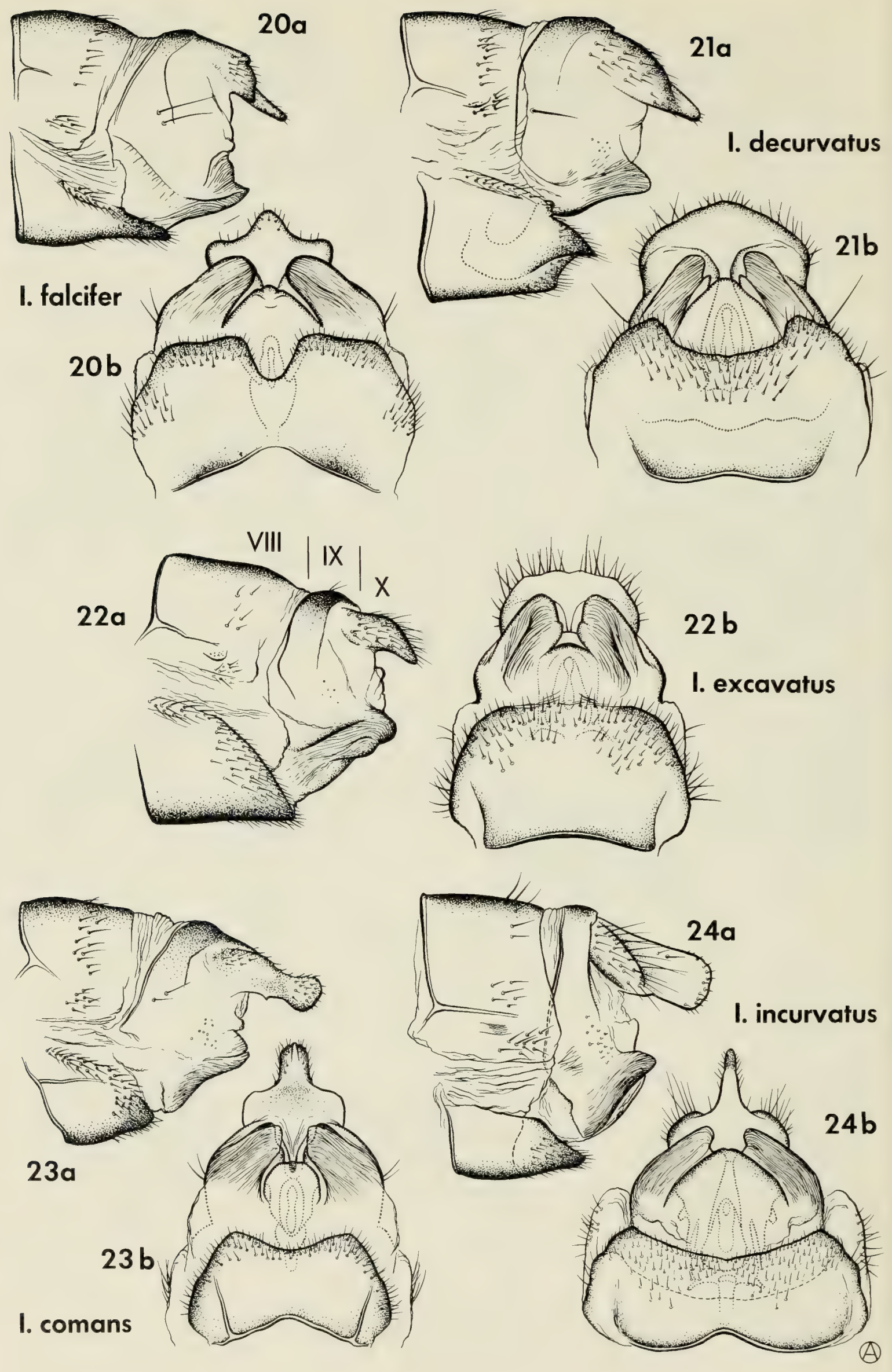

Figs. 20-24-Female genitalia in Indomolannodes spp. 20. I. falcifer sp. n. 21. I. decurvatus sp. n. 22. I. excavatus $\mathrm{sp}$. n. 23. I. comans $\mathrm{sp} . \mathrm{n}$. 24. I. incurvatus sp. n. $a$, lateral view; $b$, ventral view. 
Ventral branch of the clasper in the form of a short, stout, heavily sclerotized hook; dorsal branch of the clasper very much larger, in lateral view comprising a wide basal area and a slender terminal process. Tenth segment with dorsomedian plate triangular, the lateral margins concave in dorsal view; lateral appendages somewhat mitten-like in shape as in I. falcifer, but with the broadest part dorsad; mesal appendages each with a dorsal process in the form of a clavate strip, and with a ventral elongate, slender pointed process. Phallus much as in I. falcifer, phallotheca very broad, endothecal sclerites larger and curved, bristles on the extensile appendage pointed, ventral piece short and beak-like.

Female Genitalia (Fig. 23). Most closely resembling I. incurvatus, but distinguished by characters given in the key. Posterior margin of the eighth sternum slightly excavate in ventral view. Apex of the tenth segment extended into an elongate median process, terminating in a rounded knob.

TYPES (all collected by F. Schmid). Holotype, male: INDIA, Assam, United Jaintia and Khasi Hills: Umlangshor, $4100 \mathrm{ft}$., 18 April 1960, at light. Paratypes: INDIA, Assam, United Jaintia and Khasi Hills: Jarain, $2800 \mathrm{ft} ., 13$ April 1960, 2 o , at light; Mawpran, 3500 ft., 8 April 1960, 1 is; Mawpyut, $4000 \mathrm{ft} ., 14$ April 1960, 1. ㅇ ; Nongjni, $3750 \mathrm{ft}$., 19 April 1960, 3 of 1 \% , at light; Thangrain, $3000 \mathrm{ft}$., 22 April 1960, 1 o , at light.

The name given to this species refers to the dense coating of long hairs on the front legs of the male.

Distribution. Known only from the Khasi Hills in Assam.

HABITAT AND BIOLOGY. Adults of this species were taken only in April, and at elevations ranging from 2800 to 4100 feet, somewhat lower than some of the other species. Adults were collected at lights located close to both large and small rivers. At several localities this species was taken along with Molanna paramoesta Wiggins.

\section{Systematic Considerations}

The genera Indomolannodes and Molannodes are certainly closely related. Both show essentially the same type of venation. Basic similarity between the male and female genitalic structures is also clear, and the males in both genera possess the pair of curious pronotal pouches, as already described. The close interrelationships between the two are in contrast to those shown with Molanna, where the veins of the wings are still further reduced from the primitive condition in a very specialized way, and the wings are rolled around the body in a highly characteristic manner. The genitalic structures are quite different, with the male genitalia in Molanna showing considerable simplification in structural detail from the condition in Indomolannodes and Molannodes. The pronotal pouches are absent in Molanna. The evidence tends to support the interpretation that Indomolannodes and Molannodes represent a more primitive level of molannid evolution than does Molanna. New evidence will be available when the immature stages of Indomolannodes become known. 
If this interpretation, based entirely on morphological evidence, is correct, it relates in an interesting way to another observation. The species of Molanna are for the most part inhabitants of lakes and larger rivers, but those of Molannodes and Indomolannodes are clearly confined to cooler, lotic habitats. This invasion of more lentic, downstream-type environments by groups derived from ancestors inhabiting the cooler, upstream sections is a pattern of evolution typical for the Trichoptera (Ross 1956) and for other aquatic insect groups, too (Corbet 1962).

Within the genus Indomolannodes three groups of species are clearly evident. Comparison of male genitalia leaves little doubt that these groups comprise I. falcifer and comans, I. decurvatus and incurvatus, and I. excavatus. Analysis of the female genitalic structure lends no particular support to these groupings, but neither does it militate strongly against them. It is of interest to see that in I. excavatus, the one species of the genus in which $\mathbf{M}_{1}$ and $\mathbf{M}_{2}$ are separated in the fore wing of the male and thus the same as Molannodes in this respect, the structure of the phallus also shows a strong similarity to that of Molannodes.

Some generalization concerning the distribution of the species of Indomolannodes seems appropriate, especially in view of the extensive collecting which was carried out in these areas by Dr. Schmid. From present evidence, the only species living in the Himalayas is I. incurvatus, which extends from Garhwal (west of Nepal) to the Kameng Frontier Division (northern Assam, east of Bhutan). Its close relative I. decurvatus is known from Burma and Manipur (eastern Assam). Of the second group, I. falcifer is known from Manipur and the Khasi Hills, and I. comans from the Khasi Hills alone. The remaining species $I$. excavatus is known only from Manipur. Four of the five known species of Indomolannodes, representing all three species groups, are, then, evidently confined to Assam and western Burma, strongly suggesting that the radiation of these species did occur there.

Of the species of Molanna, evidence of the enormously high ecological versatility of $M$. paramoesta is seen from the fact that its distribution extends over much of the Indian subcontinent, where it occurs in a wide variety of habitats at elevations ranging from 200 to 7400 feet. The Siberian and Japanese counterpart of this species, M. moesta, is also very widespread, and it must be concluded that these two species represent an extremely viable and adaptable segment of the Molannidae. By contrast, the two Indian species here recognized for the first time, Molanna saetigera and crinita, are evidently so highly specialized for their montane environment that they have been unable to exploit the lower elevations as $M$. paramoesta has done. And these two Indian species of Molanna show no close relationship with others of the genus. 


\section{Key to the Holarctic Genera of the Molannidae}

1. Dorsum of head with a single pair of lateral, elongate warts (Fig. 10)

Dorsum of head with two pairs of small lateral warts (Fig.

Molanna

2. Clasper of male comprised of a single piece of regular outline, somewhat triangular in lateral view; fore wing of male with $\mathbf{M}_{1}$ and $\mathbf{M}_{2}$ separate, as in the females

Molannodes

Clasper of male highly complex, comprised of a dorsal and a ventral branch, the dorsal branch usually slender and finger-like, the ventral branch usually hook-like (Figs. 13-19); fore wing of male with $M_{1}$ and $M_{2}$ united (usually), and thus distinct from the females (Fig. 16).... Indomolannodes

\section{Acknowledgments}

My appreciation is extended to Dr. Schmid for the opportunity of studying this extremely interesting collection. Dr. H. E. Evans, Museum of Comparative Zoology, Harvard University, kindly made it possible for me to study the holotype of Molanna moesta Banks. Additional Asian specimens of Molanna of assistance in clarifying the status of Molanna falcata Ulmer were loaned by Dr. O. S. Flint of the U.S. National Museum. All illustrations were prepared by Mr. Anker Odum, artist in the Department of Entomology and Invertebrate Zoology, Royal Ontario Museum.

\section{Literature Cited}

BANKS, N.

1906 New Trichoptera from Japan. Proc. Ent. Soc. Wash., vol. 7, nos. 2-3, pp. 106-113.

CORBET, P. S.

1962 A biology of dragonflies. H. F. \& G. Witherby, London. 247 pp. FISCHER, F. C. J.

1964 Trichopterorum catalogus. Vol. V. Phryganeidae; Limnocentropodidae; Molannidae. Nederlandsche Entomologische Vereeniging, Amsterdam. 214 pp.

MARTYNOV, A. V.

1910 Les Trichoptères de la Sibérie et des régions adjacentes. II-e partie. Ezheg. Zool. Muz., vol. 15, pp. 351-429.

1937 Trichoptera of the Amur region. Part I. Trudy Zool. Inst., Leningr., t. II, 1933-35, pp. 205-395.

NIELSEN, A.

1957 A comparative study of the genital segments and their appendages in male Trichoptera. Biol. Skr., vol. 8, no. 5, 159 pp. 
ROSS, H. H.

1952 The caddisfly genus Molannodes in North America. Ent. News, vol. 63 , no. 4 , pp. 85-87.

1956 Evolution and classification of the mountain caddisflies. Univ. Illinois Press, Urbana. 213 pp.

TSUDA, $\mathrm{M}$.

1942 Zur Kenntnis der koreanischen Trichopteren. Mem. Coll. Sci. Kyoto Univ., ser. B, vol. 17, no. 1, art. 5, pp. 227-237.

ULMER, G.

1908 Japanische Trichopteren. Dt. Ent. Z., vol. 3, pp. 339-355. 

(c) $\ln ^{4}$ 

